\title{
Analytical Model of Bolted Joint Structure and Its Nonlinear Dynamic Characteristics in Transient Excitation
}

\author{
Xin Liao, ${ }^{1}$ Jianrun Zhang, ${ }^{1}$ and Xiyan $X \mathrm{u}^{2}$ \\ ${ }^{1}$ School of Mechanical Engineering, Southeast University, Nanjing 211189, China \\ ${ }^{2}$ School of Science, University Autonoma of Madrid, 28049 Madrid, Spain \\ Correspondence should be addressed to Jianrun Zhang; zhangjr@seu.edu.cn
}

Received 25 July 2016; Revised 19 September 2016; Accepted 4 October 2016

Academic Editor: Emiliano Mucchi

Copyright (c) 2016 Xin Liao et al. This is an open access article distributed under the Creative Commons Attribution License, which permits unrestricted use, distribution, and reproduction in any medium, provided the original work is properly cited.

\begin{abstract}
The dynamic response of crucial components often depends upon the dynamic behavior of bolted connections. As is usually the case, the accurate modeling of structures with many mechanical joints remains a challenge work. The nonlinear behavior included in assembled structures strongly depends on the interface properties. In this paper, an analytical model of the simple bolted joint beam in tangential direction is first proposed for transient excitation, based on phenomenological model. The fourth-order Runge-Kutta method is employed to calculate the transient response, where the dynamic response of the nonlinear stiffness on system is also investigated. The simulation results show that natural frequency has a certain dependence on cubic stiffness term and cubic stiffness is more suitable for modeling of nonlinear system of a wider frequency range. Thereby, a series Iwan model containing cubic stiffness term is established to describe nonlinear behaviors of bolted joint beams in shear vibration. The amplitude-frequency curves show that the influence of interaction between nonlinear stiffness and damping mechanism on dynamic response characteristics is more obvious. Finally, a new type of nonlinear model is applied into finite element analysis. The results of proposed transient excitation experiment are discussed qualitatively, indicating that nonlinear effects observed agree with the numerical simulation results.
\end{abstract}

\section{Introduction}

The mechanical behavior of the bolted joint structure under vibration has long been characterized and studied in the context of engineering machinery, including modeling and experiments methods. Dynamic analysis and evaluation have been studied the most in order to achieve expected effects of vibration or minimize the undesirable behaviors [1-4]. The nonlinear characteristics of bolted joint interface are of great interest because of their influence on structural vibration, which can even be detrimental to overall dynamics. Most of researchers have investigated some complicated characteristics by building different dynamic systems. And in the contribution, measured and simulated frequency response functions (FRFs) are commonly considered to identify nonlinear joint characteristics or analyze the dynamics of an assembly for a specific input-output behavior.

Bolted joint provides localized high stress during fastening, which brings more considerations for modeling works and design. For specific structural designs and practical working conditions, researchers require simulating and predicting the dynamic behaviors of such a bolted joint structure, which is also a crucial safety assessment. The finite element method is widely used in all kinds of research for bolted joint properties. Pratt and Pardoen [5] proposed nonlinear finite element models to predict the load-elongation behavior of conical-head bolted lap joints, and simulation results were compared with test data. Kim et al. [6] developed four kinds of finite element models to analyze the pretension effect and contact behavior of bolted joint structure. Shuguo et al. [7] studied the dynamic effects of bolted and spline joints in the aeroengine rotor using finite element method and evaluated the influence of typical parameters on critical speed and vibration modes. Additionally, interface modeling approaches are also studied by many researchers; for example, Miller and Quinn [8] used a series-series Iwan model together with an elastic chain to carry out the simulation of frictional damping for bolted joint structure, 
which significantly reduced the computational requirements. Grosse and Mitchell [9] demonstrated that external loading could soften or stiffen the joint for various test configurations. Jalali et al. [10] established a detailed parameter model of bolted joint interface and identified the parameters of model by force-state mapping method. Although there have been already many accepted modeling approaches, more detailed descriptions for the structure with bolted joint in modeling are still inadequate due to nonlinear joint properties and the lack of theoretical analytical relationship [11].

The bolted joint interface of interest between two bodies introduces both linear and nonlinear dynamic at the same time, which is a common challenge in experimental precision and design. Modal testing and analysis have always been widely used in studies [12-14]. Lawlor et al. [15] presented an experimental study on the effects of variable bolt-hole clearance in double-lap, multibolt joints. For bolt self-loosening phenomenon, impulse tests of bolted joint are also measured by some researchers. Although there have been already some experimental researches of bolted joint structure for various loading conditions, few reports have been found on the transient excitation in tangential direction, which plays an important role in shear vibration.

Until recently researchers have focused on nonlinear damping and stiffness characteristics in bolted joint interface and also nonlinear dynamic behavior of bolted joint structure. Through some reviews about theory and experiment, Ouyang et al. [16] studied damping behavior evolving from linear viscous type to nonlinear frictional type with a bolted joint test fixture. The experiments conducted by Hartwigsen et al. [17] also revealed that damping behavior had large influence on the dynamic response of bolted joint structure. Furthermore, some nonlinear damping models are established and applied in numerical simulation. Similarly, nonlinear stiffness models have also been developed and used gradually [18]. The expression of stiffness term and its correlation coefficient in system are particularly important due to simulation calculation totally depending on equations with the parameters. Thus, the types of stiffness applied within the coupling element affect dynamic response characteristics of system directly and determine if nonlinear behavior can be described accurately. Ahmadian and Jalali [19] simulated a stiffness-softening effect, which was symptomatic of a cubic stiffness term in the model, in a joint structure. Experimental studies [16] also showed that odds number of superharmonics in the frequency spectra seem to suggest that a cubic stiffness term would be useful in simulating dynamic behavior of bolted joint. Budnitzki et al. [20] discussed the effect of cubic stiffness on fatigue characterization resonator performance and used a parametric optimization strategy to minimize the cubic stiffness.

Even though various nonlinear models for the bolted joint structure have been applied in the dynamic researches, analytical modeling approach in transient excitation still needs to be further developed due to complexity of interface. In addition, the transient excitation of shear direction can cause deflection of vibration for bolted joint structure, resulting in changes of whole dynamic performance, or eventually leading to bolt relaxation and fatigue fracture caused by nonuniform force. Up to now, there have been few published studies that integrated nonlinear stiffness with damping in modeling of bolted joint interface to capture system's dynamic characteristics under mutual interactions of the two in transient excitation. Therefore, the purpose of the present work is to develop a nonlinear dynamic model of bolted joint structure and investigate the influence of nonlinear factors of bolted joint interface on system dynamic characteristics in transient excitation. To this end, an analytical model for simple bolted joint structure is first proposed based on phenomenological model, and the dynamic responses of system under different nonlinear stiffness parameters are analyzed. Then, considering the tangential stiffness and friction damping of interface related to bolt preload, a series Iwan model and cubic spring stiffness are combined to describe different dynamic behaviors, stick-slip, and macroslips. The amplitude-frequency curves for different excitation levels and preload levels in shear vibration are analyzed, respectively. Meanwhile, the new series Iwan model is added to the finite element analysis. Finally, the correlative transient excitation experiments are carried out to validate good agreement with the simulation results.

\section{Nonlinear Modeling of Bolted Joint Beam}

2.1. Dynamics Model. The proper theoretical modeling for a system assemblies is a key part of evaluating dynamic characteristics. The aim of modeling approach diversity is to help understand the behavior of the system better, especially the types on nonlinearities in play. For some experimental results [17, 21], a linear model cannot match data acquired accurately. The tangential stiffness is often neglected or assumed to be rigid in modeling, such as the content in literature [22]. Therefore, it can be noticed that how to build the analytical model accurately in tangential direction is very important for the dynamics analysis under transient excitation, but the related content has not been described in detail for bolted joint structures in earlier investigations. In this part, a kind of common bolted joint structure in practical engineering is first introduced, as shown in Figure 1. The four plates, which are made of low-carbon steel, are employed to be bolted together by the way of a double shear lap joint. All the rectangular steel plates have a length of $250 \mathrm{~mm}$ and width of $100 \mathrm{~mm}$ and a thickness of $5 \mathrm{~mm}$. The shear lap region locates in its center. The study considers M12 bolts with metric mechanical property class 8.8 .

In order to analyze the dynamics characteristics of the test case in Figure 1 in transient excitation, the double shear lap joint structure is simplified to be a discrete model with 2 degrees of freedom (DOF) based on phenomenological model, as seen in Figure 2, where $m_{1}$ and $m_{2}$, respectively, represent the mass of the upper and lower plates. The transient excitation is loaded in tangential direction.

In this system, the equation of motion can be written as

$$
\begin{aligned}
& m_{1} \ddot{x}_{1}+c_{1} \dot{x}_{1}+k_{1} x_{1}+c_{2}\left(\dot{x}_{1}-\dot{x}_{2}\right)+k_{2}\left(x_{1}-x_{2}\right) \\
& \quad+k_{3}\left(x_{1}-x_{2}\right)^{3}=0,
\end{aligned}
$$




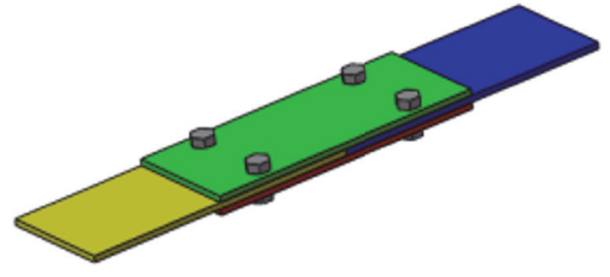

(a)

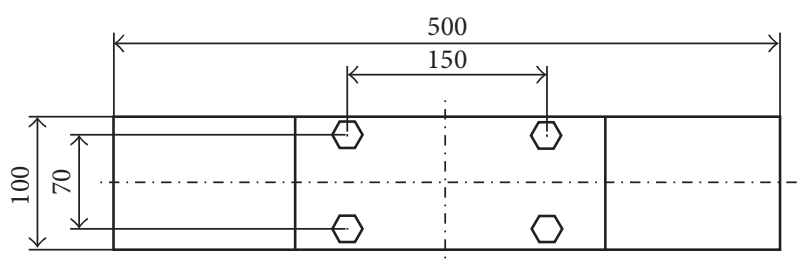

(b)

FIGURE 1: The double shear lap joint structure. Green: top plate; red: bottom plate; yellow and blue: middle plate.

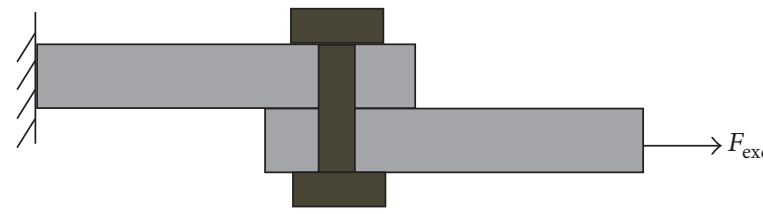

(a)

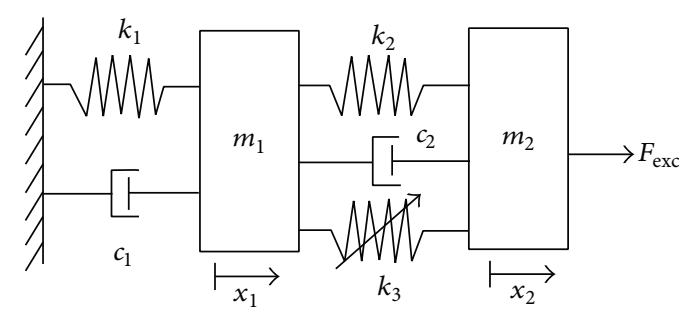

(b)

FIGURE 2: Two-degree-of-freedom (DOF) nonlinear model.

$$
\begin{aligned}
& m_{2} \ddot{x}_{2}+c_{2}\left(\dot{x}_{2}-\dot{x}_{1}\right)+k_{2}\left(x_{2}-x_{1}\right) \\
& \quad+k_{3}\left(x_{2}-x_{1}\right)^{3}=F_{\mathrm{exc}}
\end{aligned}
$$

where $x_{1}$ and $x_{2}$ are the displacement values, dots represent derivatives with respect to time, $c_{1}$ and $c_{2}$ are the viscous damping coefficients, $k_{1}$ and $k_{2}$ are linear spring stiffness values, $k_{3}$ is cubic spring stiffness, and $F_{\text {exc }}$ is the excitation force. Here, a cubic stiffness nonlinearity in tangential direction is employed to allow the system modal frequencies to increase with impact levels, which is just reflected in the results of modal tests. The cubic stiffness term has a very small effect for small deflections when linear behavior occurs, because maybe linear and nonlinear factors exist at the same time in the system. In addition, for the transient excitation, when impact amplitude becomes much larger suddenly, the deflection amount of cubic spring will bring about more nonlinearity, especially in the case of low preload. Actually, choosing the cubic stiffness term contributes to supplementing an extra increase of stiffness. The transient excitation is easier to excite the cubic stiffness due to instantaneous increased preload caused by instant impact. Furthermore, from the point of view of the working principle of construction machinery, when establishing the dynamics model under special working conditions, such as large impact level, cubic stiffness term just makes up for the lack of total stiffness. For example, the excavator cab is susceptible to impact with larger amplitude in working; thus analytical model of vibration isolation system of cab contains cubic stiffness term, and in addition cubic stiffness provides more elastic support [23]. Similarly, in the study of dynamics modeling of wind turbine blade, the calculation result of differential equation including cubic stiffness term appears more reliable [24]. Hence, based on the reasons above, the cubic spring stiffness is chosen
TABLE 1: Simulation parameters of the numerical system.

\begin{tabular}{lc}
\hline Parameter & Value \\
\hline$m_{1}=m_{2}(\mathrm{~kg})$ & 0.5 \\
$c_{1}=c_{2}(\mathrm{Ns} / \mathrm{m})$ & 0.02 \\
$k_{1}=k_{2}(\mathrm{~N} / \mathrm{m})$ & 1 \\
$k_{3}\left(\mathrm{~N} / \mathrm{m}^{3}\right)$ & 0.05 \\
$F_{\text {exc }}(\mathrm{N})$ & $40,100,150$ \\
\hline
\end{tabular}

in modeling. To study the influence of bolt preloads and excitation levels on the amplitude response depending on time, the fourth-order Runge-Kutta method is employed to solve the coupled differential motion equation (1) to obtain the frequency responses of the two-DOF nonlinear system under the transient excitation. The calculated time step is $2 \times 10^{-4}$ seconds. The simulation parameters of the system are given in Table 1.

2.2. Transient Excitation. The expression of transient excitation normally has a small difference in shape when impulse is much faster than the response speed. Here, the impact levels are adjusted by the hammer as excitation inputs and the duration of the impact is approximately one millisecond. Then, taking $40 \mathrm{~N}$ and $100 \mathrm{~N}$, for example, of low and high excitation amplitudes, respectively, their impact excitation curves for high and low level hits are shown in Figure 3.

\section{Numerical Results and Analysis}

When the bolted joint beam is subjected to transient excitation, the magnitude of excitation amplitude maybe changes the dynamic response properties of the whole under the action of complicated factors. Therefore, investigating various 


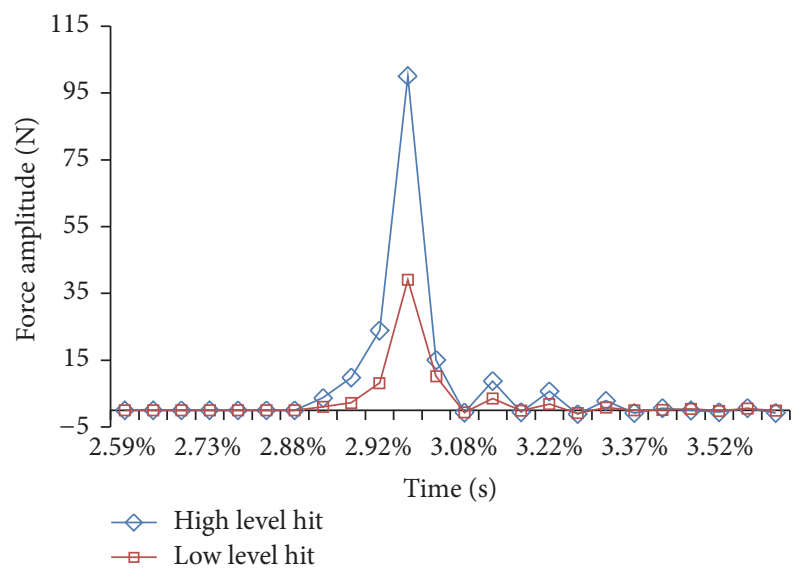

FIGURE 3: Impact force for simulation.

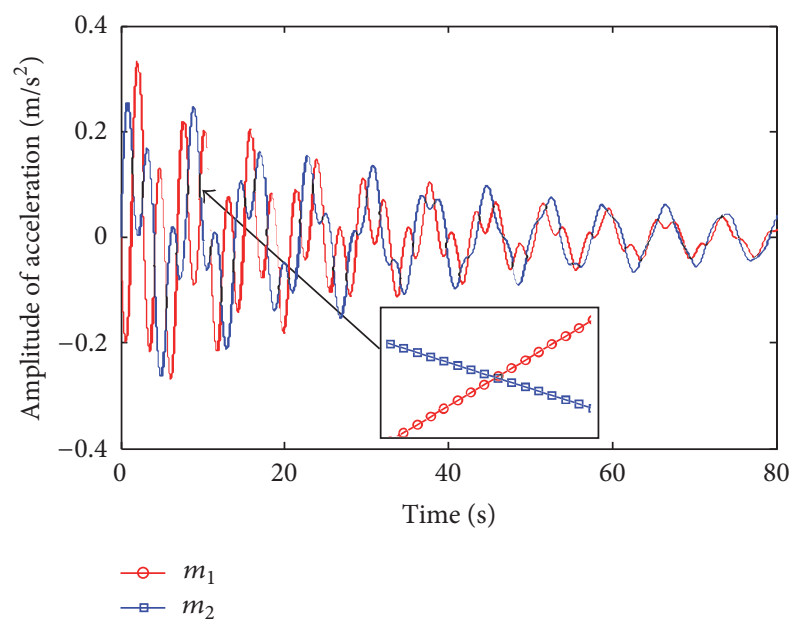

FIGURE 4: Mass acceleration time histories.

excitation amplitude levels and bolt preloads contribute to describing nonlinear dynamic behavior. Figure 4 shows the calculated acceleration of mass in the transient response. In this system response, it can be found that the amplitude of acceleration of the first mass decreases more than that of the second mass during the period of first twenty seconds. And then the decline rate of their amplitude acceleration becomes consistent basically.

It can be seen that the amplitudes of acceleration for frequency response curves change a lot under different impact levels in Figure 5, and the corresponding frequencies variation basically keeps unchanged. However, Figure 6 shows that the nonlinear effects are more visible in the acceleration amplitude curves normalized by the impact level. In Figure 7, the bolt torque is gradually increased by means of a constant increment. Similarly, it can be found that there are some changes in the amplitudes of acceleration and frequencies corresponding to the peaks during an impact. This simulating result illustrates that dynamic response characteristics have dependence on bolt preload and impact amplitude level, and the cubic spring is very sensitive to the preload changes within a certain range. When the bolts are forced with

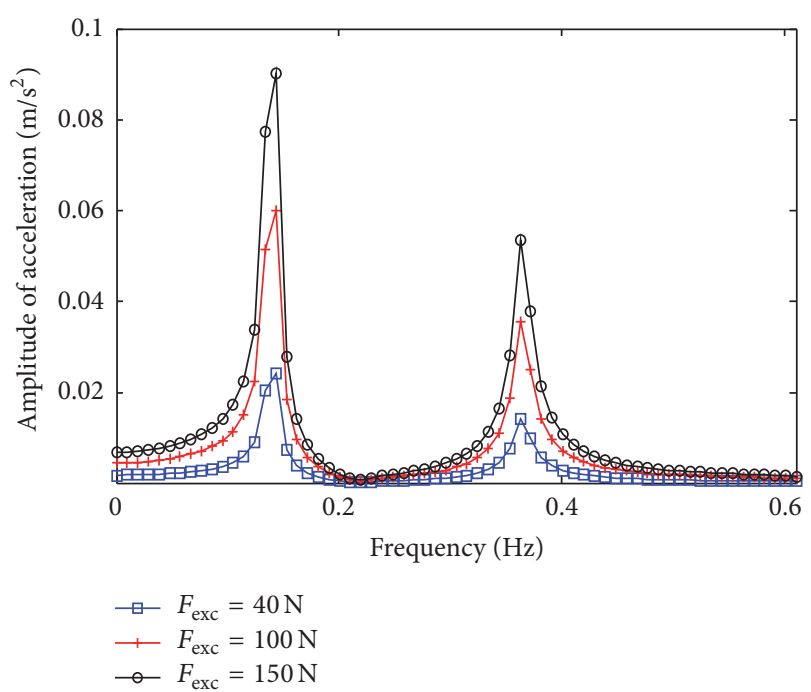

FIGURE 5: The comparison of frequency response curves for different excitation amplitudes.

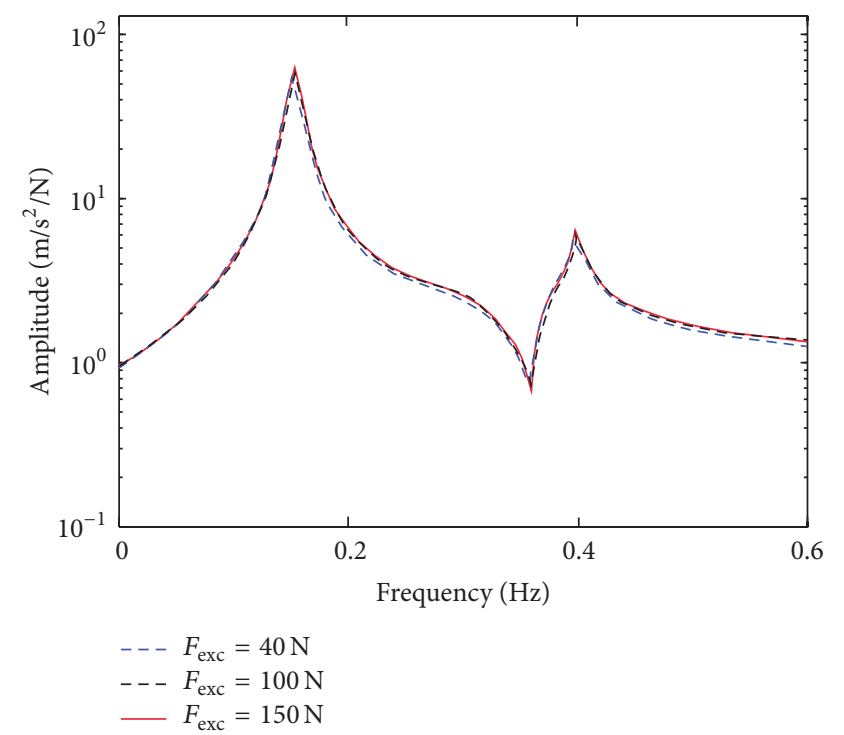

FIGURE 6: The normalized acceleration amplitude curves for various excitation amplitudes at torque $=8 \mathrm{~N} \cdot \mathrm{m}$.

increasing torque, damping and stiffness parameters of the interface are changed and especially the cubic stiffness term is excited by normal compression that increases joint stiffness.

Based on the datum analysis above, the bolt preload contributes to the changes of cubic stiffness term, which also has a certain impact on the dynamic properties of system. Similarly, to study the effect of the cubic stiffness term in detail, some new numerical analysis with different parameters are carried out. From Figure 8, it can be observed that the amplitude-frequency curves with various cubic stiffness parameters are different when the values of $k_{1}$ and $k_{2}$ are kept unchanged. The frequency domains corresponding to the peaks seem to become wider, even though the peak 


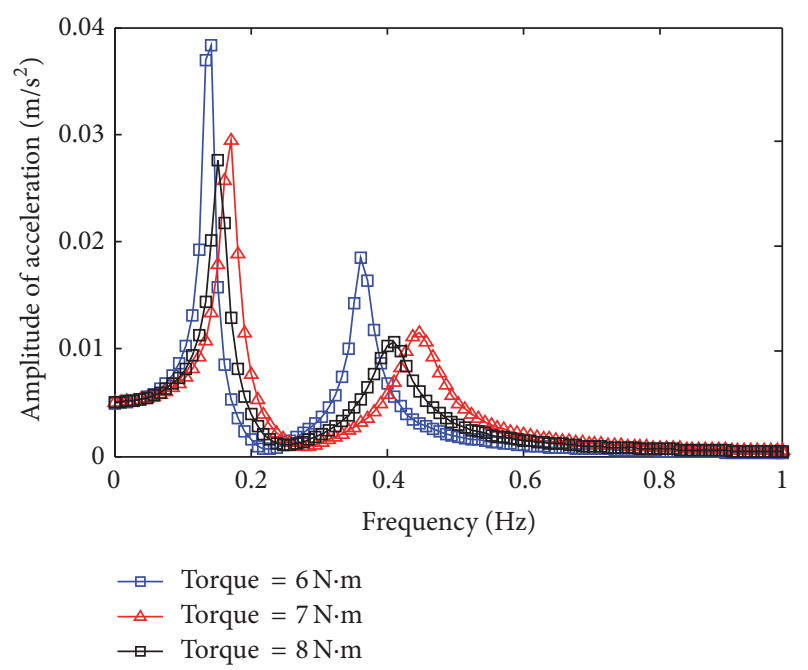

FIGURE 7: The comparison of frequency response curves for different torques when the force amplitude $F_{\text {exc }}=100 \mathrm{~N}$.

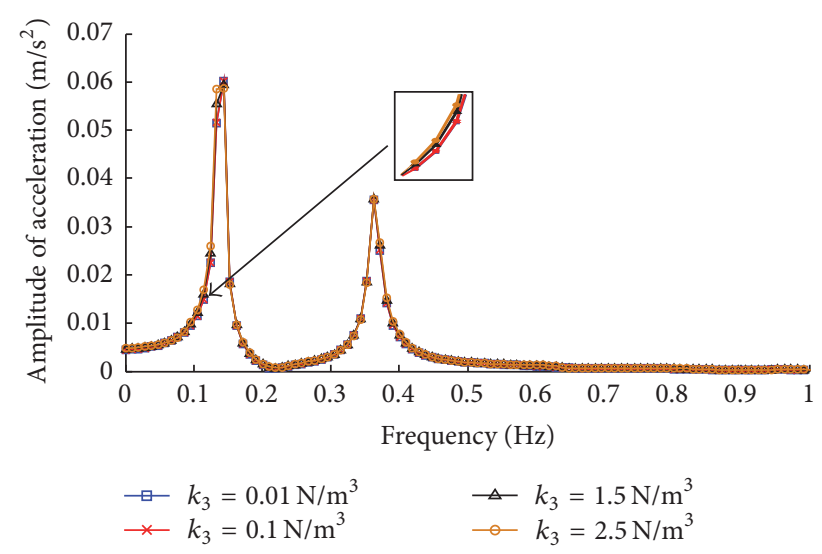

FIGURE 8: The comparison of frequency response curves for varying cubic stiffness parameters.

frequencies change little. Its nonlinear phenomenon is not very obvious.

However, when we change $k_{1}$ and $k_{2}$ in process of varied cubic stiffness, two peak values of amplitude-frequency curves and natural frequencies occur changing obviously; meanwhile the frequency domains for peak values are getting wider, which can be seen in Figure 9. But the broadening extent decreases as the values of $k_{1}$ and $k_{2}$ increase. It also indicates that natural frequency has smaller dependence on cubic stiffness term. However, by the effect of cubic spring stiffness, the amount of frequency variation corresponding to the second peaks is more than that corresponding to the first peaks. The results reveal that, comparing with low frequency region, cubic stiffness term has more influence on dynamic response characteristics or becomes more sensitive to nonlinear system at some extent, in relative higher frequency region. Therefore, the cubic stiffness nonlinearity can be employed accurately in modeling, especially when nonlinear system is excited in a larger frequency range. Moreover, in practical engineering application, the impact forces across the interface often change, especially when instantaneous strong impact converts low frequency vibration into high frequency vibration; it will be easier to cause slapping mechanism. Thus, the interaction between the cubic stiffness term and damping mechanism and their influence on nonlinear dynamic characteristics will be discussed next.

\section{Series Iwan-Type Model}

Mechanical joints have an important influence on structural dynamic response, in which nonlinear stiffness and damping are primarily concerned. Also, damping is the important source of system energy dissipation. Therefore, in order to describe dynamic behavior of bolted joint structure better and accurately, a series-series Iwan model can be applied into the modeling of the whole system for stick-slip and macroslip phase. Figure 10 shows the Iwan series-series model comprised of a series of Jenkins elements. Each Jenkins unit consists of a linear spring and a Coulomb slider. However, combined with the cubic spring, a new Iwan model is proposed, as shown in Figure 11. A single Jenkins element is in parallel with a cubic spring. The friction contact is characterized with the Coulomb friction coefficient $\mu$. The different kinematic states of the Iwan element, stick-slip, or macroslip are determined by a critical slipping force $F_{f}$, which indicates the onset of macroslip.

In this model, two different states are, respectively, considered. In the stick-slip phase, the stiffness is determined by $K_{1}$ and $K_{2}$. In the macroslip phase, the stiffness of original Iwan model's system will become zero when the system reaches its ultimate force $f_{y}$, and $K_{2}$ will disappear. However, the remaining cubic spring stiffness just makes up the rigidity of the system at the onset of macroslip. Also, there is an equivalent slipping friction force instead, and the $K_{1}$ spring elements are in series with each other, which is represented as in the discrete system

$$
\frac{1}{\sum K_{1}}=\frac{1}{K_{1,1}}+\frac{1}{K_{1,2}}+\cdots+\frac{1}{K_{1, n}},
$$

where we assume that all of stiffness values $K_{1, n}$ are equal. The extended nonlinear model is shown in Figure 12. The motion equation can be rewritten as

$$
\begin{aligned}
m_{1} \ddot{x}_{1}+c \dot{x}_{1}+k x_{1}+F_{I} & =0, \\
m_{2} \ddot{x}_{2}+F_{I} & =F_{\text {exc }},
\end{aligned}
$$

where $F_{I}$ is the nonlinear inner force calculated in series Iwan model due to deformation, $k$ is linear spring stiffness, and $c$ is viscous damping coefficient.

On the basis of the above discrete models, new amplitudefrequency curves including friction damping are obtained. Figure 13 shows the frequency response results of variable interactions. It can be seen that the peak frequencies and amplitudes did change slightly with the variation of ultimate force and cubic stiffness parameter, which indicates that the nonlinear effects can be visible by modeling in stickslip phase and closely related to the preload. In addition, these curves seem not to be very smooth and there are 

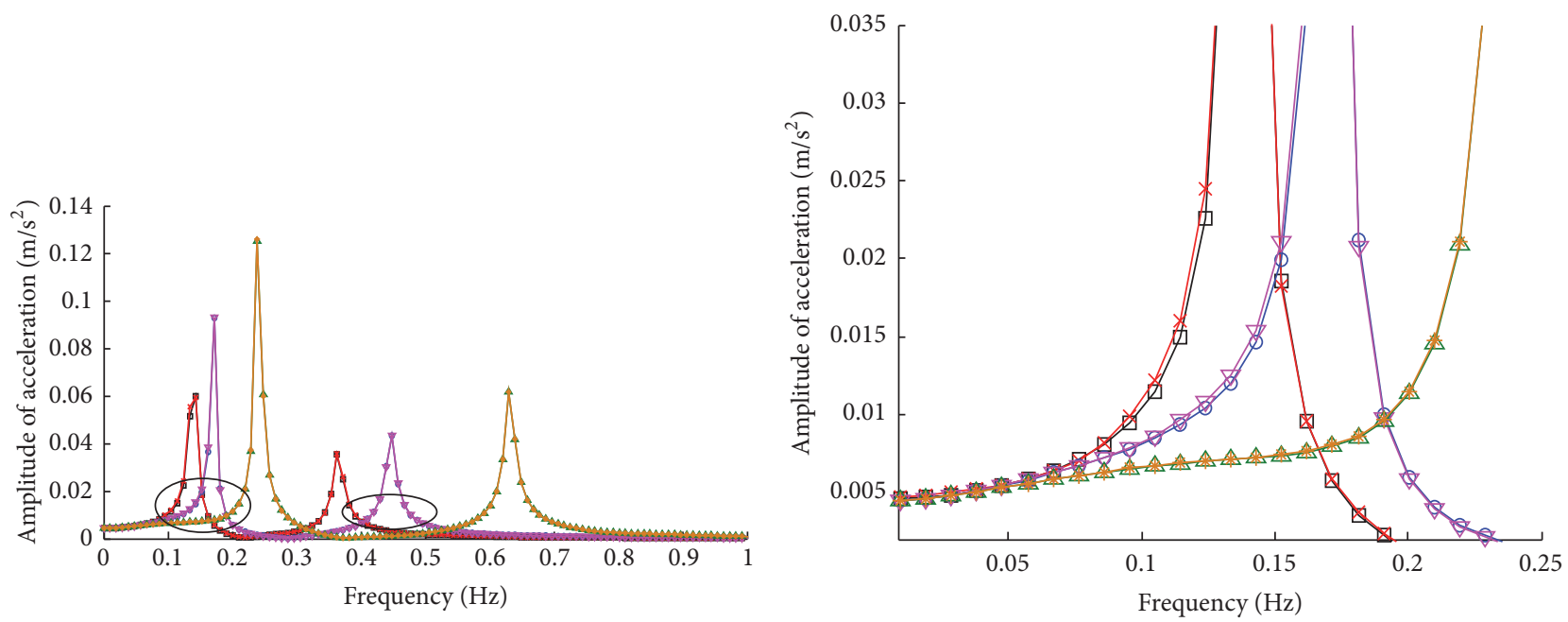

$\square-k_{1}=k_{2}=1.0 \mathrm{~N} / \mathrm{m}, k_{3}=0.1 \mathrm{~N} / \mathrm{m}^{3}$
$\rightarrow-k_{1}=k_{2}=1.0 \mathrm{~N} / \mathrm{m}, k_{3}=1.5 \mathrm{~N} / \mathrm{m}^{3}$
$\rightarrow-k_{1}=k_{2}=1.5 \mathrm{~N} / \mathrm{m}, k_{3}=0.1 \mathrm{~N} / \mathrm{m}^{3}$
$\rightarrow-k_{1}=k_{2}=1.5 \mathrm{~N} / \mathrm{m}, k_{3}=1.5 \mathrm{~N} / \mathrm{m}^{3}$
$\triangle k_{1}=k_{2}=3.0 \mathrm{~N} / \mathrm{m}, k_{3}=0.1 \mathrm{~N} / \mathrm{m}^{3}$
$\rightarrow-k_{1}=k_{2}=3.0 \mathrm{~N} / \mathrm{m}, k_{3}=1.5 \mathrm{~N} / \mathrm{m}^{3}$

(a)

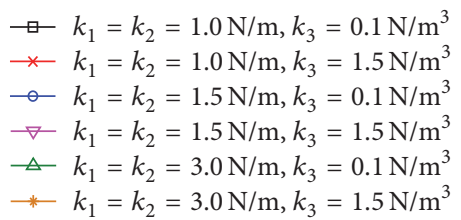

(b)

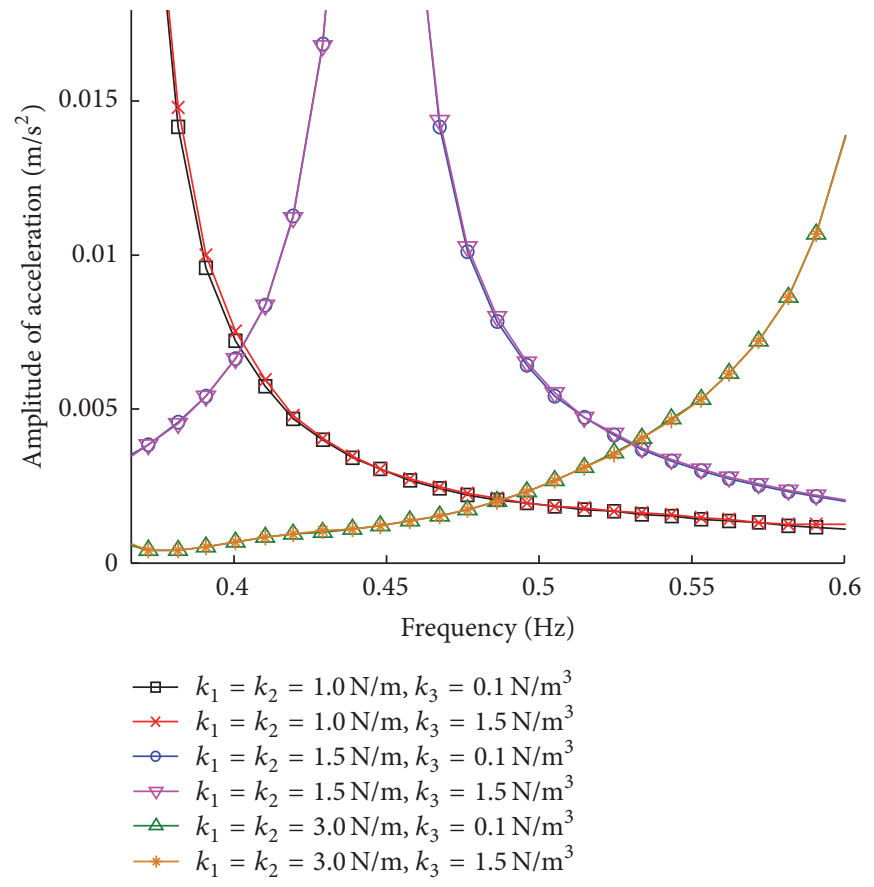

(c)

Figure 9: The comparison of frequency response curves for varying cubic stiffness when $k_{1}$ and $k_{2}$ are changed. (a) Effect of cubic stiffness term. (b) Local enlarged view from left circle. (c) Local enlarged view from right circle.

some small peaks appearing compared with the previous graphs. It illustrates that the addition of series-series Iwan model excites the smaller amplitudes on frequency region in nonlinear dynamic system. From another point of view, when the nonlinear damping and nonlinear stiffness element are simultaneously included in the series Iwan model, the nonlinear stiffness can represent more accurate dynamic characteristics by simulation modeling in the case of the transient excitation once the jointed structure starts macroslip. Furthermore, for the bolted joint structure with larger damping under transient excitation, the simulation model with series Iwan element has an important influence on judgment and evaluation working of whole machine dynamic response. 


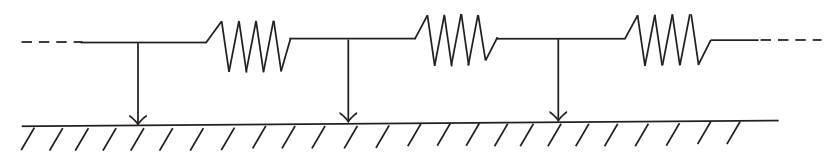

FIGURE 10: Iwan's one-dimensional series-series model.

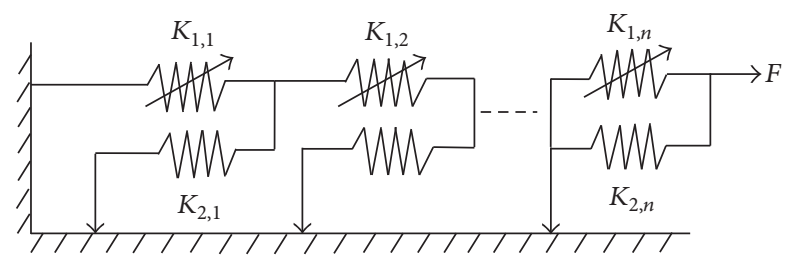

FIGURE 11: A new series Iwan model.

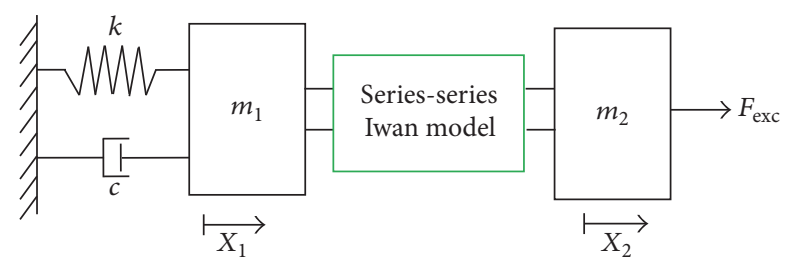

FIgURE 12: Two-degree-of-freedom nonlinear model with series Iwan element.

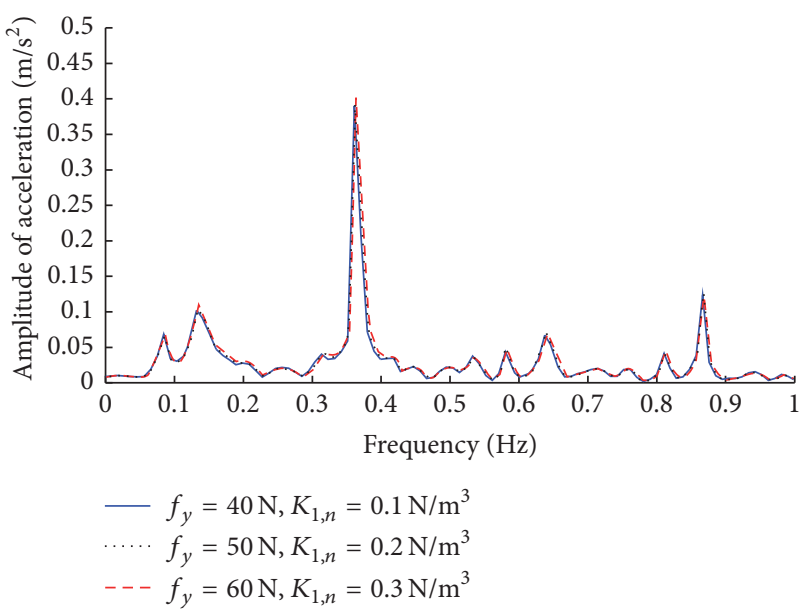

FIGURE 13: The comparison of frequency response curves for different parameters when the force amplitude $F_{\text {exc }}=100 \mathrm{~N}$.

Figure 14 is the schematic of the transfer function between the acceleration of mass $m_{1}$ and the input excitation. With the addition of the nonlinear damping model to the dynamic system, it can be observed that the natural frequency and amplitude change with bolt preloads.

The resulting FRFs for each torque show that the nonlinear effects are obvious. When the magnitude of torque is tuned to increase, the peak values change a little larger

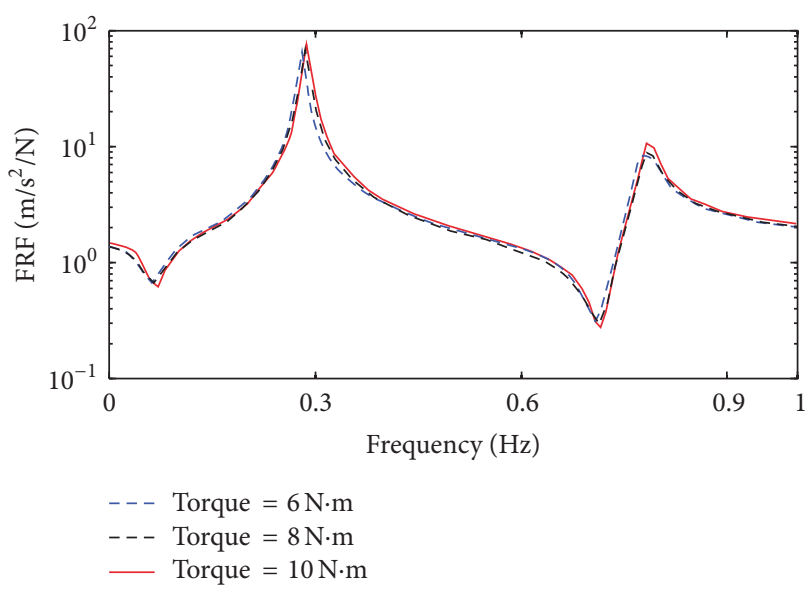

FIGURE 14: Comparison of frequency response functions for various bolt torque levels when the force amplitude $F_{\text {exc }}=100 \mathrm{~N}$.

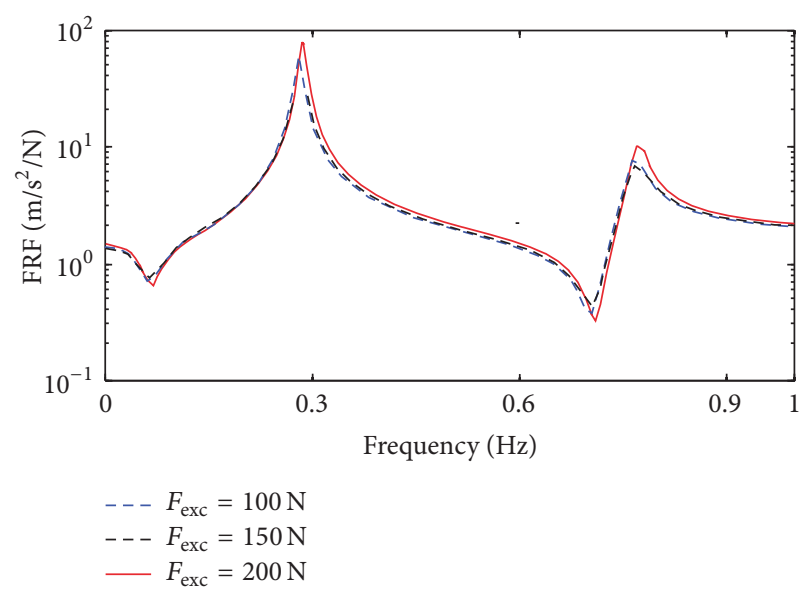

FIGURE 15: Comparison of frequency response functions for various excitation levels at torque $=8 \mathrm{~N} \cdot \mathrm{m}$.

than before and the width of peaks also becomes more wider under the interaction of nonlinear coupling element, which indicates that the model takes on stiffening trend gradually. Figure 15 shows FRFs for different excitation levels under the same tightening force. These plots reveal that the natural frequency first does not change much significantly with the increasing excitation amplitudes, but the increments of peak values become a little larger when the excitation level reaches a greater value. It indicates that the dependence of natural frequency on the impact level is small even though the system nonlinearity behavior is stronger in low preload level. Also, it can be found that the peaks for impact level $100 \mathrm{~N}$ are higher than those for impact level $150 \mathrm{~N}$. This seems to result from a certain mode excited with increase in damping and the assumed extent of hit is certainly not large for bolted joint structure in tangential direction. Besides, in this above case, the calculation is only gone on under relative lower tightening force of bolts. 


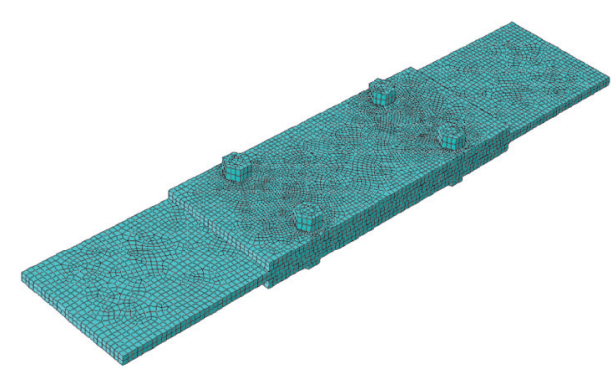

(a)

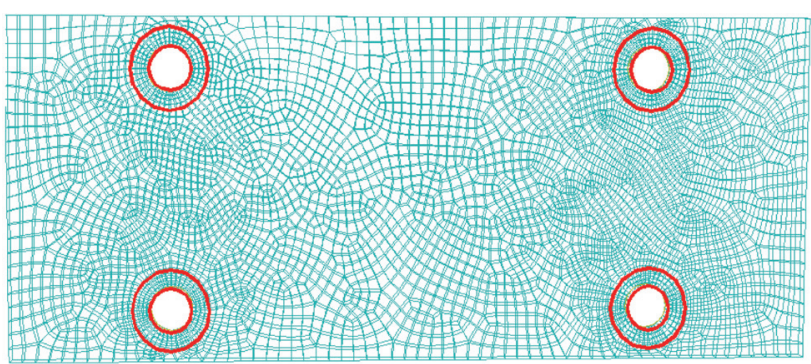

(b)

FIGURE 16: Finite element model: (a) global model; (b) local mesh.

\section{Modeling of the Double Shear Lap Joint Beam with Bolts}

In order to investigate the influence of bolted joint interface on the dynamics of the connected structure, a detailed finite element model for composite beam structure with bolted joints is developed in ABAQUS, as shown in Figure 16(a), which totally consists of 67306 elements and 79493 nodes. The thickness of each plate is represented by double rows of mesh elements. In addition, the finite element model for a similar beam structure consisting of narrower plates jointed with 4 screws is also built. The tangential stiffness of the joint is closely related to the normal load, which plays an important role in shear vibration of transient excitation. Thus the tangential and normal stiffness are both considered in our finite element analysis. First, since the contact nonlinearity is primary consideration in the prestressed model of bolted joint, the contact relationship between components is built through using surface-to-surface contact and the masterslave algorithm. The main contact pairs are defined as the annular regions around bolt holes, whose outer radius increases by about $85 \%$ compared with radius of bolt hole, as shown in Figure 16(b). This is because stress distribution area in linear system basically concentrates in the range, and also different mesh densities are assigned, respectively, on annular regions and other regions on the plates, which is helpful to obtain reliable simulation results.

According to the relationship between selected torque $T$ and bolt tension $F$, the equivalent normal load applied to the bolt and nut can be calculated by the following equation [25]:

$$
T=K F D \text {, }
$$

where $K$ is the dimensionless nut factor, which is approximately equal to 0.2 for all cases, and $D$ is the nominal diameter of the bolt.

In this model, there are the calculations of multiple load steps, including the bolt preload as the first analysis step and the subsequent transient load step imposed on composite beam structure. By application of Lagrange's approach, the general form of equation for the composite beam system is given by

$$
\mathrm{M} \ddot{\varphi}+\mathrm{C} \dot{\varphi}+\mathrm{K} \varphi+\mathrm{F}_{\mathrm{I}}=\mathrm{F}_{\mathrm{exc}}
$$

where $\boldsymbol{\varphi}$ is vector of generalized displacements, $\mathbf{M}$ is mass matrix, $\mathbf{C}$ is damping matrix, $\mathbf{K}$ is stiffness matrix, $\mathbf{F}_{\mathbf{I}}$ is nonlinear inner force matrix, and $\mathbf{F}_{\text {exc }}$ is vector of transient excitation force. The dynamic explicit reduced integration is used to mesh the whole model designated element type C3D8R. The normal behavior in contact is considered to be hard contact. The properties of the elastic elements and series Iwan elements are as follows: elastic modulus $E=$ $2.1 \times 10^{5} \mathrm{MPa}$, Poisson ratio $\lambda=0.3$, and density $\rho=$ $7.85 \times 10^{3} \mathrm{~kg} / \mathrm{m}^{3}$. Based on the contact algorithm, nonlinear stiffness matrix is inserted into the computational model and the initial forcing vector is gradually updated when every Iwan element undergoes a transition from stick to slip in transient excitation. The obtained simulation results are, respectively, compared with experimental data in the following section.

\section{Transient Excitation Experiments}

To evaluate the effect of various preloads and impact levels on the nonlinear dynamic behavior in bolted joints, a series of experiments are performed to understand system response characteristics under transient excitation. Then, this measured dynamic response data can contribute to the comparison with a theoretical model, thereby predicting the accuracy or extracting the relevant data to facilitate the simulation calculation and parameter identification, and so forth. For this purpose, the experimental system is set up, as shown in Figure 17. There are two triaxial sensors which are, respectively, arranged near the front and back ends. The sensors chosen are PCB Model 356 B08 with a $10 \mathrm{mV} / \mathrm{m} / \mathrm{s}^{2}$ sensitivity and the hammer is PCB Model 086C03 with a $2.25 \mathrm{mV} / \mathrm{N}$ sensitivity. The data acquisition and analysis system used in this study is $m+p$ international SO Analyzer with 8 channels (VXI Mainframe rack unit, Agilent E8491B). In order to ensure the reliability of the experiment, three impacts have been carried out for each excitation force and then averaged [26]. The four bolts are tightened to a predefined torque with a torque wrench, and the cross section of right end of the double shear lap beam is impacted with the hammer. During this period of testing, bolt preload levels are adjusted in turn to be $4 \mathrm{~N} \cdot \mathrm{m}, 8 \mathrm{~N} \cdot \mathrm{m}$, and $12 \mathrm{~N} \cdot \mathrm{m}$, and coherence function is kept well in experiments. 


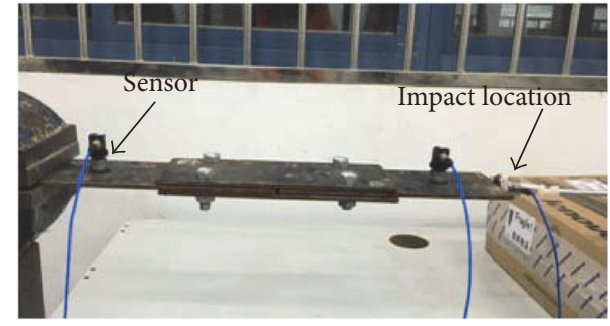

FIGURE 17: Double shear lap beam experimental setup.

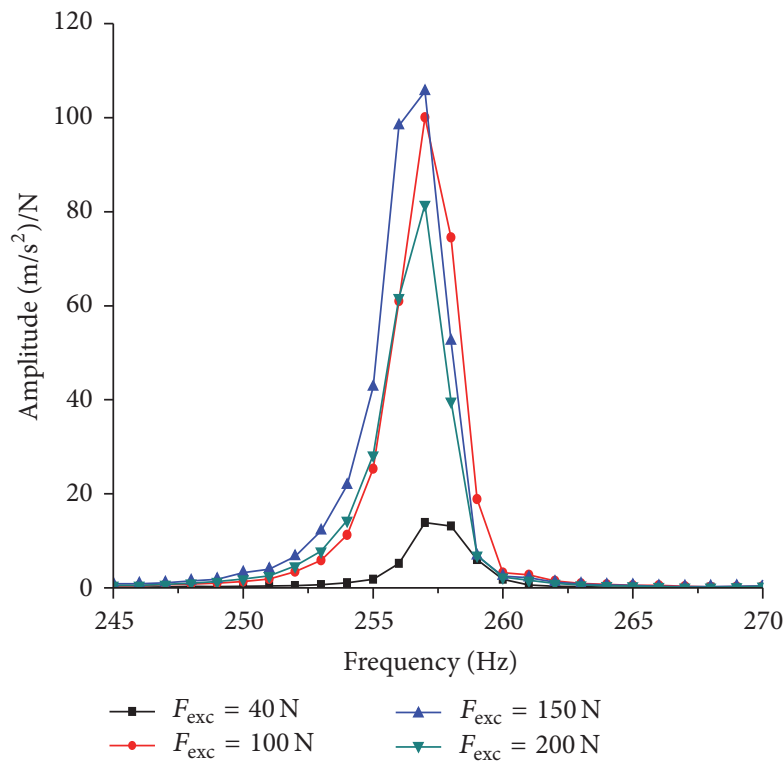

FIGURE 18: Frequency response functions of the second mode under different impact levels.

Figure 18 is a plot of the transfer function between the accelerometer on the left side of the beam structure and the input force, as shown in Figure 17. The major modal frequency is about $258 \mathrm{~Hz}$ and almost identical in the four cases. With increasing of the impact level, the variation of natural frequency is very small and the change tendency of amplitude of acceleration is generally similar to the results in Figure 5. It can be conjectured that the cubic stiffness in tangential direction has small influence on dynamic behavior of system, in the process of impact. Moreover, when the impact level is higher, we can see that the amplitude value suddenly becomes more smaller than those in other cases due to the effect of the nonlinear damping. In Figures 19 and 20, it is evident that as the applied impact level is increased, the response characteristics in the second mode have obvious changes, especially the natural frequency whose trend increases with the preload levels. Similarly, the correlative nonlinear stiffness parameter and damping coefficient will change at the same time when the bolt torque is increased slowly. In particular, the influence of cubic stiffness on dynamic response characteristics mainly is reflected in a certain range in the process of increasing torque. If the torque is too small, the coupling damping is small which

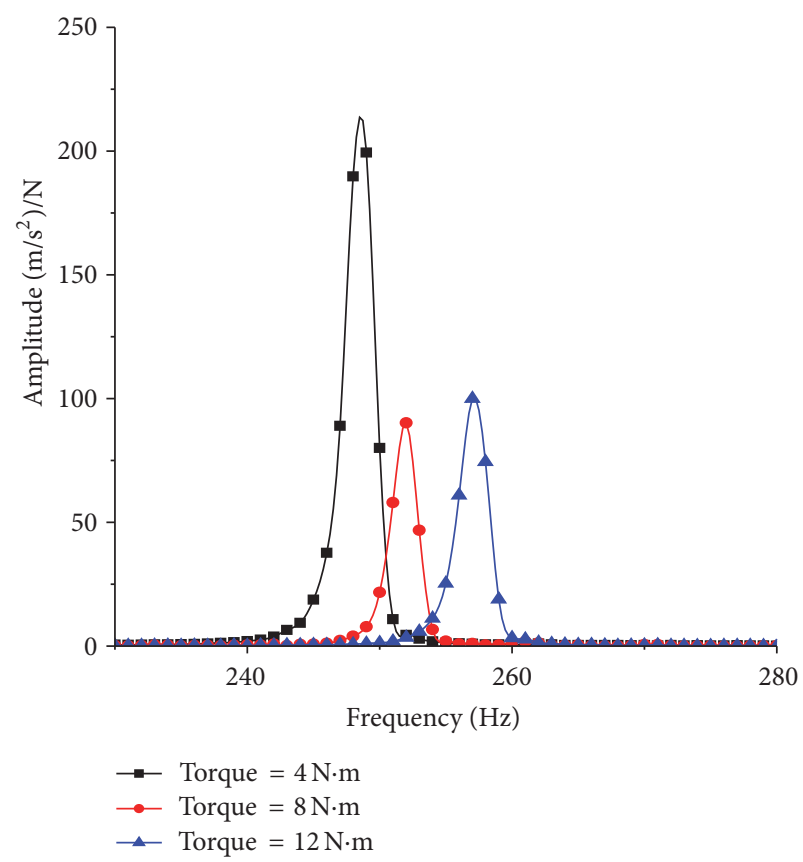

FIGURE 19: Frequency response functions of the second mode with impact levels $F_{\text {exc }}=100 \mathrm{~N}$.

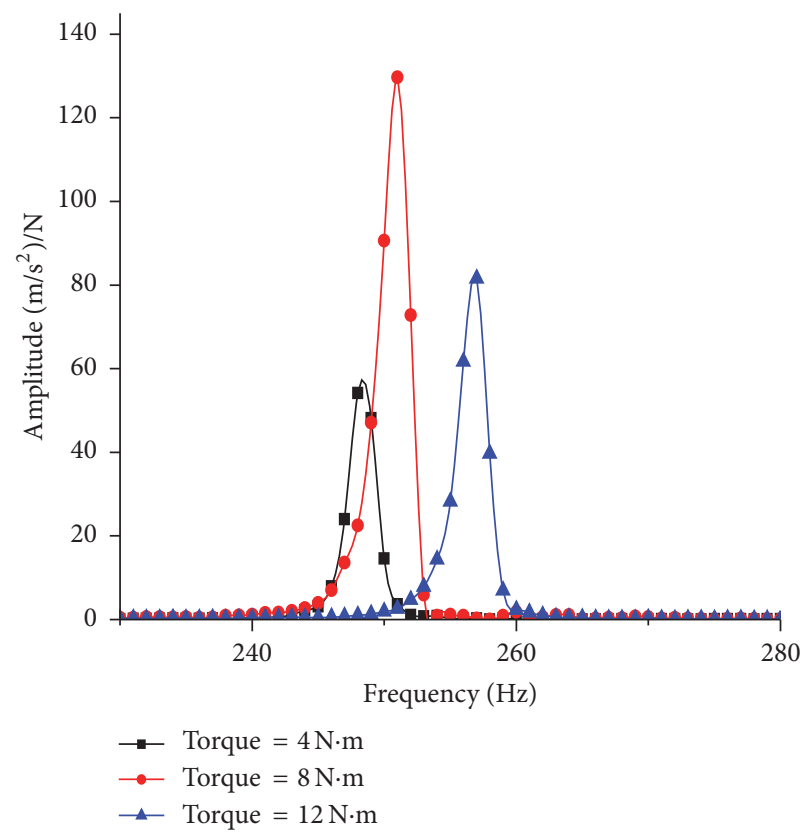

FIGURE 20: Frequency response functions of the second mode with impact levels $F_{\text {exc }}=200 \mathrm{~N}$.

can cause extra rotation of local system at some extent, and the effect of cubic stiffness term is almost insignificant in nonlinear system. If the bolt is screwed too tightly, the cubic stiffness term becomes insensitive to the preload. Also, in some specific dynamic cases, for example, when the double shear lap joint structure is subjected to large impact force or 


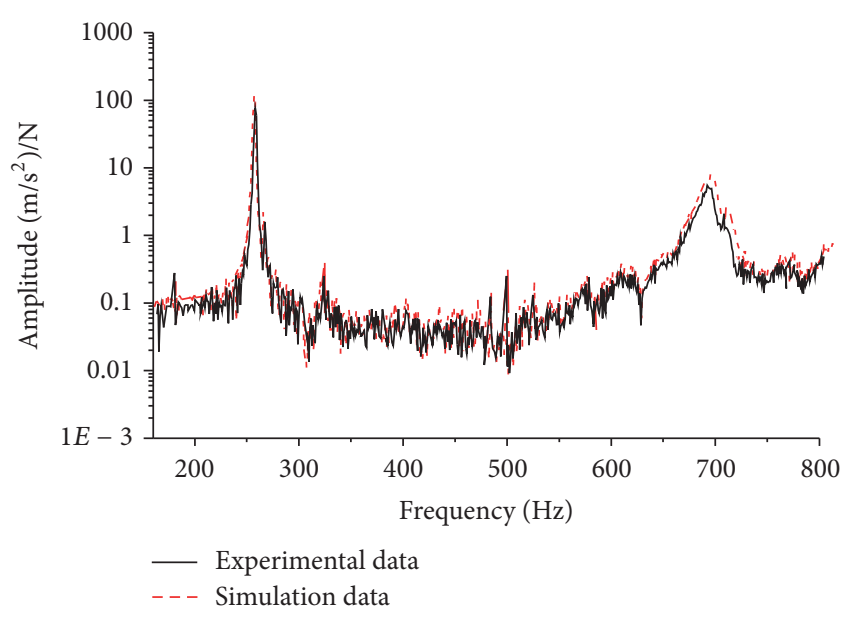

(a)

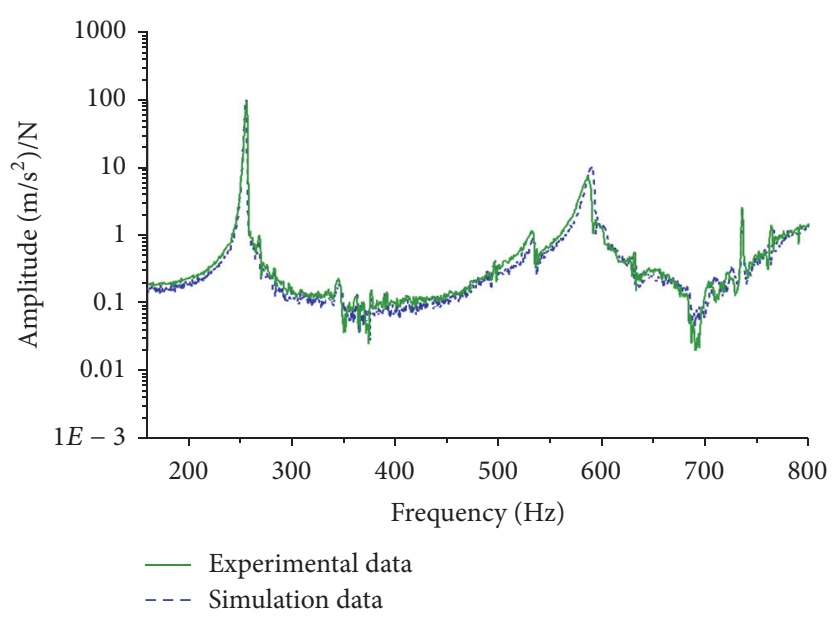

(b)

Figure 21: Comparison of frequency response functions obtained by experiential data and finite element analysis results at torque $=8 \mathrm{~N} \cdot \mathrm{m}$. (a) The double shear lap beam jointed with 4 screws. (b) The similar beam structure consisting of narrower plates jointed with 2 screws.

high frequency excitation, the clapping damping mechanism will play a major role rather than the cubic stiffness term. Moreover, these two figures even illustrate that experiment phenomena agree with the numerical results in Section 3, except for the orders of magnitude. In addition, the response amplitudes are also examined for various preload levels in the double shear lap beam. The magnitude of the peaks does not always keep decreasing with increasing of preload levels, however, which can be seen in Figure 19. It shows that the acceleration amplitude has a slight increase when torque increases from $8 \mathrm{~N} \cdot \mathrm{m}$ to $12 \mathrm{~N} \cdot \mathrm{m}$ in the experiments, which appears as if certain natural frequency can be excited better by impulse force in some cases. Figure 20 indicates that due to the increase of impact level the peaks for low preload level appreciably become smaller compared with those in Figure 19, and structural damping is also increased, resulting from more relative motion between plates. Finally, for the above two kinds of double shear lap joint beam structures, the comparisons of finite element analysis results with the full experimental data containing all modes of the system are, respectively, shown in Figure 21. It can be seen in the plot that the curves match well for several major modes of interest, where the accuracy of the simulation results is also verified and the resulting FRFs accurately reflect the dynamic behaviors.

\section{Conclusion}

In this work, the dynamic response characteristics of a double shear lap joint structure in transient excitation are investigated. Based on phenomenological model, an analytical model of simple bolted joint beam in tangential direction is developed under transient excitation. The system's nonlinear dynamic characteristics are studied and the effect of nonlinear stiffness parameters on frequency response of bolted joint structure is also investigated.

In the analysis of transient excitation, the numerical simulation results show that the cubic spring is very sensitive to the preload changes only within a certain range in the process of increasing toque. When only changing the cubic stiffness parameter, the variety of natural frequency is not very obvious in nonlinear system, which indicates that natural frequency has a smaller dependence on cubic stiffness term. However, for a wider frequency range, especially in the higher frequency region, the cubic stiffness term is more suitable for modeling of nonlinear system. Additionally, nonlinear influence in transient excitation is also observed by a new series Iwan model containing cubic stiffness term, which is also applied in the finite element calculation. The result indicates that overall nonlinear performance of double shear lap joint beam for the low preload case is reflected more evidently than before.

A series of transient excitation experiments are conducted on the bolted joint beam, and the nonlinear behavior for variable preloads and impact force levels is investigated. The results show that the changes of amplitude and natural frequency in the frequency domain plot agree with the numerical simulation results through qualitative discussion and analysis.

The numerical model for bolted joint structure proposed in this paper can be adopted to develop complicated model with multiple degrees of freedom, and a detailed investigation on dynamic response characteristics of nonlinear system can provide more help for critical structural design and mechanical application in future works.

\section{Competing Interests}

The authors declare no competing interests regarding the publication of this paper.

\section{Acknowledgments}

The authors acknowledge the Technology Grand Special Project (Approval nos. 2013ZX04012032 and 2012ZX04002032), 
Research and Development of the Key Technology for the Optimization and Reliability Design of Large High-End Paving Machine (Approval no. BE2014133), and 2014 Science and Technology Support Plan of Jiangsu China (Approval no. BE2014004-3).

\section{References}

[1] C. Antonios, D. J. Inman, and A. Smaili, "Experimental and theoretical behavior of self-healing bolted joints," Journal of Intelligent Material Systems and Structures, vol. 17, no. 6, pp. 499-509, 2006.

[2] A. Bouzid and A. Chaaban, "An accurate method of evaluating relaxation in bolted flanged connections," ASME Journal of Pressure Vessel Technology, vol. 119, no. 1, pp. 10-17, 1997.

[3] L. Gaul and R. Nitsche, "Friction control for vibration suppression," Mechanical Systems and Signal Processing, vol. 14, no. 2, pp. 139-150, 2000.

[4] S. Bograd, P. Reuss, A. Schmidt, L. Gaul, and M. Mayer, "Modeling the dynamics of mechanical joints," Mechanical Systems and Signal Processing, vol. 25, no. 8, pp. 2801-2826, 2011.

[5] J. D. Pratt and G. Pardoen, "Numerical modeling of bolted lap joint behavior," Journal of Aerospace Engineering, vol. 15, no. 1, pp. 20-31, 2002.

[6] J. Kim, J.-C. Yoon, and B.-S. Kang, "Finite element analysis and modeling of structure with bolted joints," Applied Mathematical Modelling, vol. 31, no. 5, pp. 895-911, 2007.

[7] L. Shuguo, M. Yanhong, Z. Dayi, and H. Jie, "Studies on dynamic characteristics of the joint in the aero-engine rotor system," Mechanical Systems and Signal Processing, vol. 29, pp. 120-136, 2012.

[8] J. D. Miller and D. D. Quinn, "A two-sided interface model for dissipation in structural systems with frictional joints," Journal of Sound and Vibration, vol. 321, no. 1-2, pp. 201-219, 2009.

[9] I. R. Grosse and L. D. Mitchell, "Nonlinear axial stiffness characteristics of axisymmetric bolted joints," Journal of Mechanisms, Transmissions, and Automation in Design, vol. 112, no. 3, pp. 442-449, 1990.

[10] H. Jalali, H. Ahmadian, and J. E. Mottershead, "Identification of nonlinear bolted lap-joint parameters by force-state mapping," International Journal of Solids and Structures, vol. 44, no. 25-26, pp. 8087-8105, 2007.

[11] T. F. Lehnhoff and B. A. Bunyard, "Effects of bolt threads on the stiffness of bolted joints," Journal of Pressure Vessel Technology, vol. 123, no. 2, pp. 161-165, 2001.

[12] P. Mohanty and D. J. Rixen, "Operational modal analysis in the presence of harmonic excitation," Journal of Sound and Vibration, vol. 270, no. 1-2, pp. 93-109, 2004.

[13] E. Mucchi, "Experimental evaluation of modal damping in automotive components with different constraint conditions," Meccanica, vol. 47, no. 4, pp. 1035-1041, 2012.

[14] R. J. Allemang and D. L. Brown, "A complete review of the complex mode indicator function (CMIF) with applications," in Proceedings of the International Conference on Noise and Vibration Engineering (ISMA '06), vol. 1-8, pp. 3209-3246, Katholieke Universiteit, Leuven, Belgium, September 2006.

[15] V. P. Lawlor, M. A. McCarthy, and W. F. Stanley, "An experimental study of bolt-hole clearance effects in double-lap, multi-bolt composite joints," Composite Structures, vol. 71, no. 2, pp. 176190, 2005.
[16] H. Ouyang, M. J. Oldfield, and J. E. Mottershead, "Experimental and theoretical studies of a bolted joint excited by a torsional dynamic load," International Journal of Mechanical Sciences, vol. 48, no. 12, pp. 1447-1455, 2006.

[17] C. J. Hartwigsen, D. M. McFarland, Y. Song, L. Bergman, and A. F. Vakakis, "Experimental study of nonlinear effects in a typical shear lap joint configuration," in Proceedings of the ASME Design Engineering Technical Conferences and Computers and Information in Engineering Conference, vol. 37033, pp. 1109-1116, September 2003.

[18] S. A. Nassar and A. Abboud, "An improved stiffness model for bolted joints," Journal of Mechanical Design, Transactions of the ASME, vol. 131, no. 12, pp. 1210011-12100111, 2009.

[19] H. Ahmadian and H. Jalali, "Identification of bolted lap joints parameters in assembled structures," Mechanical Systems and Signal Processing, vol. 21, no. 2, pp. 1041-1050, 2007.

[20] M. Budnitzki, M. C. Scates, R. O. Ritchie, E. A. Stach, C. L. Muhlstein, and O. N. Pierron, "The effects of cubic stiffness on fatigue characterization resonator performance," Sensors and Actuators A: Physical, vol. 157, no. 2, pp. 228-234, 2010.

[21] H. Nouira, E. Foltête, B. Ait Brik, L. Hirsinger, and S. Ballandras, "Experimental characterization and modeling of microsliding on a small cantilever quartz beam," Journal of Sound and Vibration, vol. 317, no. 1-2, pp. 30-49, 2008.

[22] Z. Y. Qin, Q. K. Han, and F. L. Chu, "Analytical model of bolted disk-drum joints and its application to dynamic analysis of jointed rotor," Proceedings of the Institution of Mechanical Engineers, Part C: Journal of Mechanical Engineering Science, vol. 228, no. 4, pp. 646-663, 2014.

[23] D. Qiu, S. Seguy et, and M. Paredes, "Design of cubic stiffness for the absorber of nonlinear energy sink (NES)," in CFA/VISHNO, pp. 2295-2300, Le Mans, France, April 2016.

[24] V. Ramakrishnan and B. F. Feeny, "In-plane nonlinear dynamics of wind turbine blades," in Proceedings of the ASME International Design Engineering Technical Conferences \& Computers and Information in Engineering Conference (IDETC/CIE '11), pp. 761-769, Washington, DC, USA, August 2011.

[25] N. Motosh, "Development of design charts for bolts preloaded up to the plastic range," Journal of Engineering for Industry, vol. 98, no. 3, pp. 849-851, 1976.

[26] J. Bendat, Engineering Applications of Correlation and Spectral Analysis, John Wiley \& Sons, New York, NY, USA, 1993. 


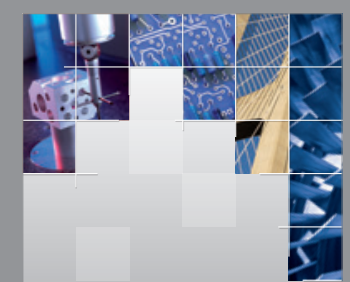

\section{Enfincering}
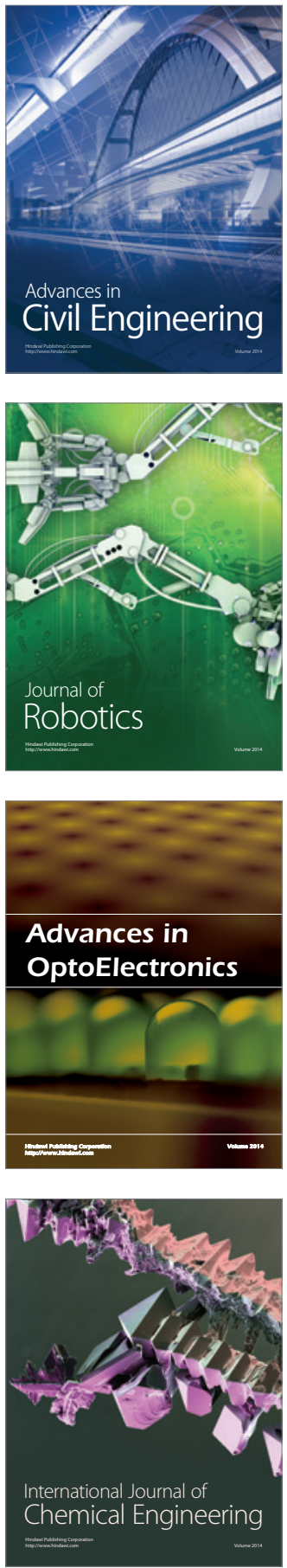

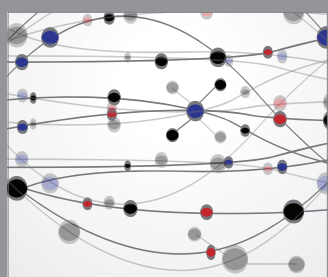

The Scientific World Journal

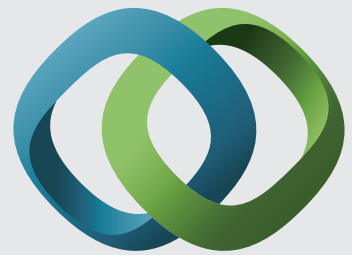

\section{Hindawi}

Submit your manuscripts at

http://www.hindawi.com
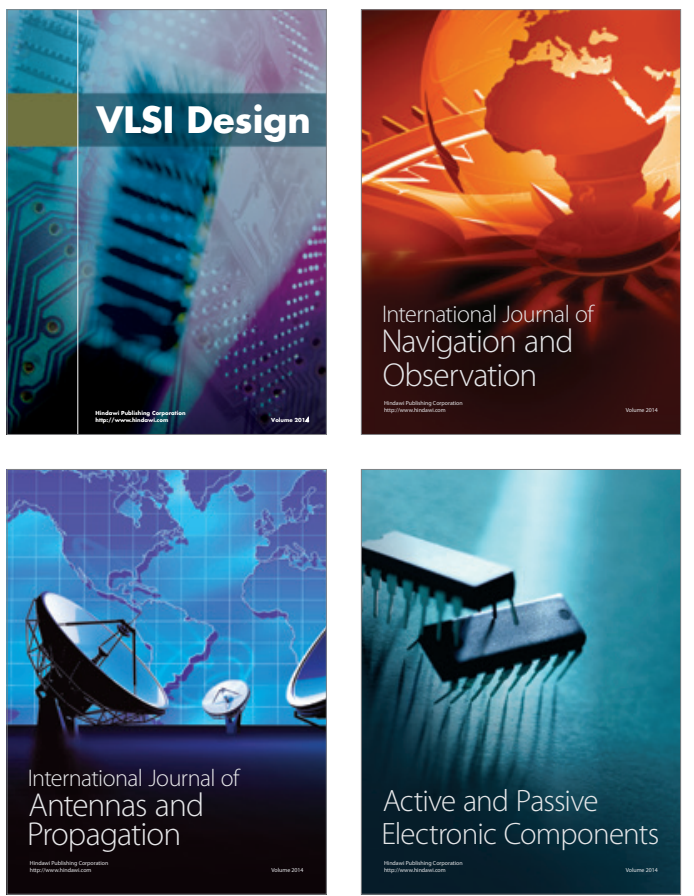
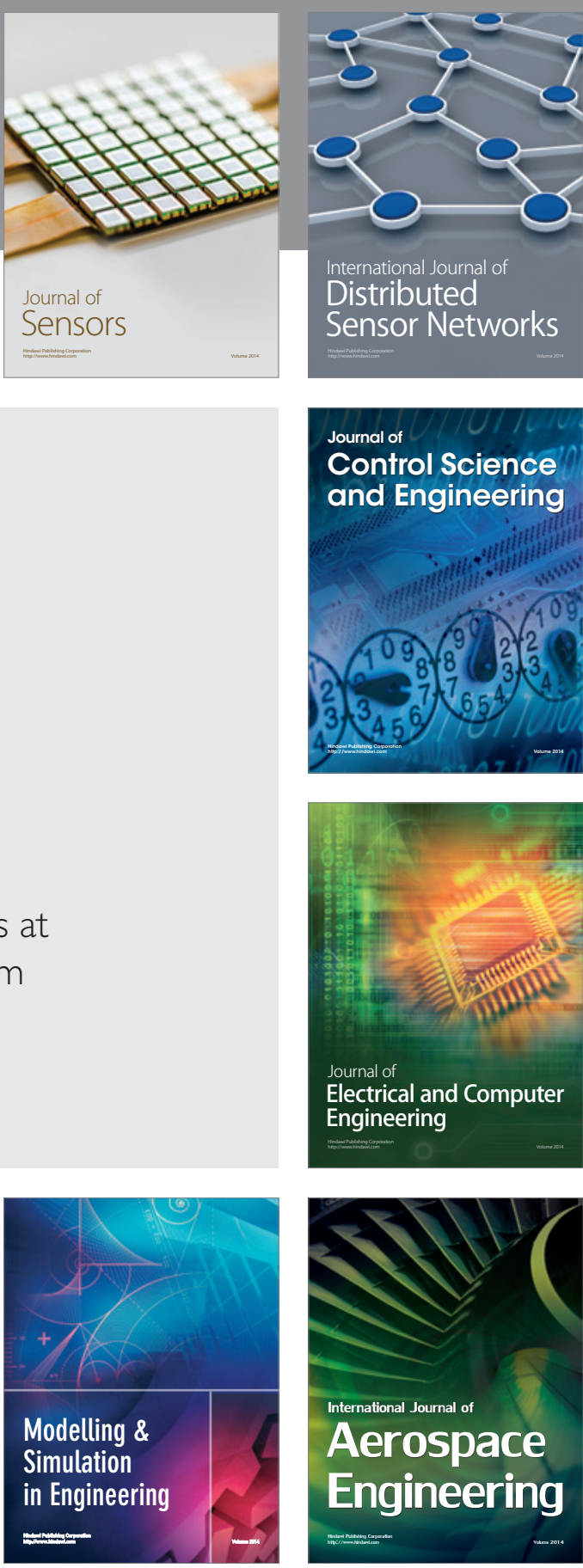

International Journal of

Distributed

Sensor Networks

Journal of

Control Science

and Engineering
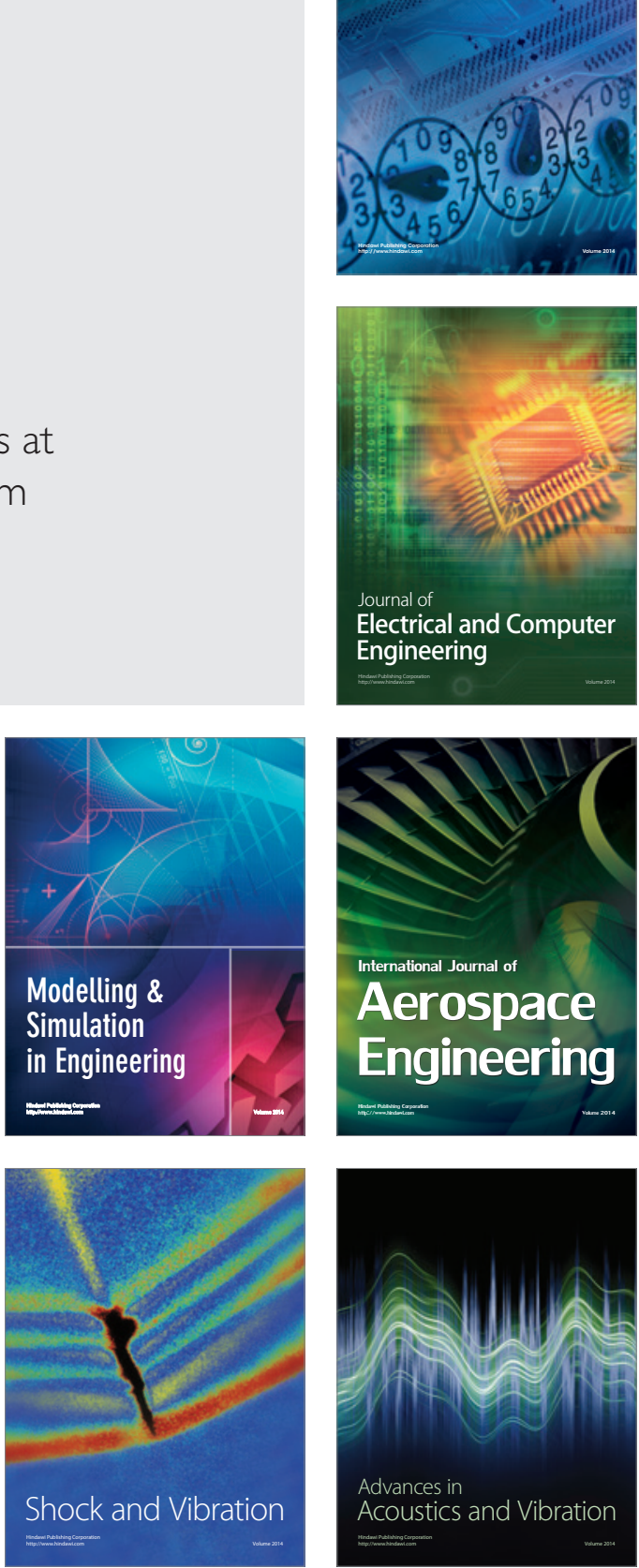